\title{
Principios para la Interpretación de los Derechos Humanos
}

Hernán Alejandro Olano García*

Director del Grupo de Investigación "Diego de Torres y Moyachoque, Cacique de Turmequé" Profesor de la Universidad de La Sabana,Chía,Colombia.

Articulo recibido: 08/08/2009 Aprobado: 25/10/2009

hernan.olano@unisabana.edu.co

Siempre se ha tenido como algo lejano poder acudir a los organismos del Sistema Interamericano en procura de la defensa de los derechos fundamentales cuando se han agotado las instancias internas. Sin embargo, nunca se ha reparado en que para poder acudir a esas instituciones, deben aplicarse criterios de interpretación que nos permitan sustentar adecuadamente las peticiones y lograr una opinión consultiva favorable anuestros intereses.

Fue Rodolfo Piza Escalante (Piza: 2003: pág 270), un antiguo magistrado de la Sala Constitucional de la Corte Suprema de Justicia de Costa Rica y luego Presidente de la Corte Interamericana de Derechos Humanos, quien realizó diversas y numerosas contribuciones al Derecho Internacional Humanitario y de los Derechos Humanos, rescatándose de la doctrina los apartes de una intervención que realizara en 1982 en el seno de la Asamblea General de las Naciones Unidas en Nueva York; de ella surgieron quince principios fundamentales del derecho de los derechos humanos, que por su importancia me permito transcribir y complementar', ya que la aplicación de estos principios, en los que se ventila la violación o amenaza de violación de derechos fundamentales internos 0 internacionales, constituye un condicionamiento importante para los tribunales constitucionales que siguen la doctrina de la Corte Interamericana y, por ende, de relevancia directa para el Derecho Procesal Constitucional:

- PrincipiodeAccionabilidad.

- Principio de Exigibilidad.

- Principio de Expansibilidad.

- Principio de Fundamentalidad.

- Principio de Humanidad.

- Principio de Imperatividad o Jus Cogens.

- Principio de Incondicionalidad.

- Principio de Indivisibilidad e Interdependencia.

- Principio de Irretroactividad-Retroactividad.

- Principio de Necesidad (Inalienabilidad)

- Principio de Prevalencia.

- Principio de Pro homine.

* Magíster en Relaciones Internacionales y Magíster en Derecho Canónico. Doctor en Derecho Canónico y estancia Post Doctoral en Derecho Constitucional como Becario de la Fundación Carolina en la Universidad de Navarra, España. Es el Director del Grupo de Investigación en Derecho Público "Diego de Torres y Moyachoque, Cacique de Turmequé", en la Universidad de La Sabana.

${ }^{1}$ Una versión más amplia puede leerse en: OLANO GARCÍA, Hernán Alejandro. Hermenéutica Constitucional. Grupo Editorial Gustavo Ibáñez, Bogotá, D.C., 2009, pp. 166-172. 
- Principio de Razonabilidad.

- Principio de Transnacionalidad (interdependencia).

- Principio de Universalidad.

\section{Principio de Accionabilidad:}

Tratándose de aquellos derechos humanos y libertades fundamentales inmediatamente atribuidos al ser humano, todo ser humano debe tener garantizado un derecho de acción autónomo para exigir el respeto y cumplimiento de tales derechos o libertades, tanto ante tribunales independientes internos, como ante organismos internacionales apropiados.

Para aquellos derechos humanos que sean legal o naturalmente dependientes de una acción progresiva por parte del Estado, cada uno y todo individuo debe gozar por lo menos: i) de un derecho de petición para demandar el cumplimiento de tales derechos, ante las autoridades nacionales. ii) de un derecho de acción autónomo para oponerse a cualquier actividad por parte del Estado que pueda impedir o retrasar el cumplimiento de tales derechos, como ante organismos internacionales apropiados.

\section{Principio de Exigibilidad:}

Sin perjuicio de su indivisibilidad e interdependencia, cada uno y todo derecho humano es disfrutable y exigible por si mismo, sin estar sujeto a ninguna condición o restricción derivada de otros derechos humanos, salvo en la medida prevista expresa y restrictivamente por el derecho internacional.

\section{Principio de Expansibilidad:}

Los derechos humanos reconocidos por el derecho internacional o nacional son mínimos y deben ser realizados de una manera expansiva, de manera que puedan ser ensanchado progresivamente mediante otros derechos humanos que se deriven de la dignidad intrínseca del ser humano.

\section{Principio de Fundamentalidad:}

Los derechos humanos son fundamentales, en el sentido de que se derivan de la intrínseca dignidad del ser humano y no de la voluntad de ninguna autoridad, la cual debe limitarse a reconocerlos, hacerlos efectivos y respetarlos.

\section{Principio de Humanidad}

(igualdad-no discriminación-):

Los derechos humanos se atribuyen a cada uno y todo ser humano por la sola razón de serlo, porigual y sin discriminación alguna, salvo aquellas autorizadas expresa y restrictivamente por el Derecho Internacional.

\section{Principio de Imperatividad (Jus Cogens):}

El Derecho de los derechos humanos, en general, forma parte del Derecho Internacional General Imperativo (jus cogens). En consecuencia:

- Sus principios fundamentales, inclusive los contenidos en la Declaración Universal de los Derechos Humanos y otros documentos en materia de derechos humanos similarmente reconocidos por las Naciones Unidas, tienen el carácter y validez de las normas imperativas del derecho internacional (Jus Cogens), con los efectos atribuidos a los mismos por la Convención de Viena sobre el Derecho de los Tratados de 1969;

- El mismo carácter, validez y efectos deben darse a los principios fundamentales del Derecho de los Derechos Humanos en los sistemas regionales reconocidos por las Naciones Unidad;

- Determinados derechos humanos específicos, reconocidos por los pactos y convenciones internacionales adoptados dentro del Sistema de las Naciones Unidas o, en su caso, dentro de los sistemas regionales reconocidos por aquéllas, deberán también ser considerados como parte de las normas imperativas del Derecho Internacional en especial aquellos que no pueden ser condicionados o suspendidos por la legislación interna o por actos autorizados por ésta;

- Los derechos humanos solamente deben ser limitados, condicionados, exceptuados 0 suspendidos en los casos y en la medida expresa y restrictivamente autorizados por los correspondientes instrumentos del Derecho Internacional; 
- Cualquier norma 0 acto, tanto internacional como nacional, que viole, suprima, modifique - restrinja derechos humanos reconocidos por una norma o principio de mayor rango de conformidad con el derecho internacional, salvo en la medida autorizada expresa y restrictivamente por éste, será nula e ineficaz.

\section{Principio de Incondicionalidad:}

Los derechos humanos implican deberes correspondientes del ser humano para consigo mismo, para con los demás hombres, para con las comunidades nacional e internacional y para con la humanidad entera, pero la titularidad y ejercicio de tales derechos no está condicionada al cumplimiento de aquellos deberes, salvo en la medida prevista expresa y restrictivamente por el Derecho Internacional.

\section{Principios de Indivisibilidad e Interdependencia:}

Los derechos humanos son indivisibles e interdependientes, en el sentido de que son atributos coherentes para la elevación y respeto de la dignidad humana y para el desarrollo armónico de todos los seres humanos en conjunto; por tanto, cada derecho humano debe hacerse eficaz de una manera congruente con los demás derechos y ninguno de una manera incongruente con los derechos de los demás seres humanos.

\section{Principio de Irretroactividad-Retroactividad: Cualquier norma que suprima, lita, restrinja o condicione los derechos humanos es irretroactiva. Cualquier norma que los reconozca, aplique, garantice 0 extienda es aplicable inmediatamente, aun respecto de situaciones consolidadas con anterioridad a la misma.}

10. Principio de Necesidad (inalienabilidad):

Los derechos humanos son indispensables para la dignidad fundamental del ser humano y para la existencia misma de la humanidad; por lo tanto, son inalienables, imprescriptibles e irrenunciables, salvo en el tanto previsto expresa y restrictivamente por el derecho internacional.

\section{Principio de Prevalencia:}

Los principios y normas de derechos humanos son de orden público y deben prevalecer sobre cualesquiera otros principios o normas de rango igual correspondientes a cualquiera otra disciplina del derecho. Lo cual sugiere una jerarquización para garantizar el derecho.

\section{Principio "Pro-homine":}

Las normas de derechos humanos deben interpretarse y aplicarse extensivamente en todo cuanto favorezca al ser humano y al pleno goce de los derechos humanos, y restrictivamente en todo lo que los excluya, restrinja y condicione o exceptúe. Los conflictos de normas deben resolverse siempre en el sentido más favorable al serhumano.

Este principio pro homine, se trata, según MÓNICA PINTO, de un "...criterio hermenéutico que informa todo el derecho de los derechos humanos, en virtud del cual se debe acudir a la norma más amplia, oa la interpretación más extensiva, cuando se trata de reconocer derechos protegidos e, inversamente, a la norma o a la interpretación más restringida cuando se trata de establecer restricciones permanentes al ejercicio de los derechos o a su suspensión extraordinaria".

Por ejemplo, en 1992, la Sala Constitucional de Costa Rica, dispuso que "El orden público, la moral y los derechos de terceros deben ser interpretados y aplicados rigurosamente, sin licencias que permitan extenderlos más de su sentido específico; sentido que, a su vez, debe verse en armonía con el principio pro libertate, el cual, junto con el principio pro homine, constituye el meollo de la doctrina de los derechos humanos; según el primero, debe interpretarse extensivamente todo lo que favorezca y restrictivamente todo 10 que limite la libertad; según el segundo, el derecho debe interpretarse y aplicarse siempre de la manera que más favorezca al serhumano".

Hay dos variaciones del principio pro homine y son el "in dubio pro operario", esto es el principio según 
el cual ha de optarse por la interpretación favorable al trabajador en caso de duda insalvable sobre el sentido de una norma, que busca afirmar la existencia de un favor debilis, es decir, una exigencia de interpretación y/o aplicación de disposición legal en el sentido que más favorezca a los trabajadores, tradicionalmente considerados como la parte débil en la relación laboral. La segunda variación es el principio pro actione, 0 "condiciones de la acción", que deben ser interpretadas en sentido favorable para posibilitar el acceso a la tutela jurisdiccional y, consiguientemente, con exclusión de toda opción interpretativa que sea contraria a ese propósito.

\section{Principio de Razonabilidad:}

Las normas de derechos humanos deben interpretarse y aplicarse de la manera que más razonablemente conduzca al cumplimiento pleno de su propósito fundamental de promover y proteger al ser humano en su integridad.

Toda excepción, suspensión, limitación o condición de los derechos humanos autorizada por el Derecho debe restringirse a lo razonablemente necesario en una sociedad democrática, para proteger los derechos humanos de otras personas, para garantizar la seguridad de todos ellos o para cumplir las justas demandas del bien común.

La discrecionalidad en el campo de los derechos humanos debe estar limitada, en general, por los principios del Derecho de los Derechos Humanos, y sujeta a fiscalización judicial en cuanto a su razonabilidad fundamental, su justicia y el respeto a la dignidad humana.
Toda conclusión a la que se llegue, será favorable a la viabilidad del proceso constitucional siempre que no resulte patente la inconsistencia del razonamiento que lleva al órgano judicial a individualizar cierta regla general como norma de la decisión.

\section{Principio de Transnacionalidad (Interacción):}

Los derechos humanos reconocidos por el Derecho Internacional deben ser vinculantes por sí mismos en el Derecho interno, con el rango de las normas constitucionales.

Los derechos humanos reconocidos por el derecho interno deben ser vinculantes para el Estado correspondiente, como normas de carácter internacional, mientras no sean incompatibles con el derecho internacional.

La misma interacción debe existir entre los derechos humanos reconocidos por el Derecho Internacional universal y regional, con respecto a los Estados que pertenezcan a ambos.

\section{Principio de Universalidad (Internacionalidad):}

Los derechos humanos son universales, en el sentido de que su reconocimiento, aplicación y respeto son obligaciones intrínsecas de cada ser humano, sociedad o Estado, y de la comunidad internacional, y de que ellos caen bajo el ámbito y jurisdicción tanto del derecho nacional como del internacional.

La protección procesal de los derechos humanos impone, en consecuencia, que exista el proceso adecuado a los fines a tutelar $y$, de ahi, que sea necesario el conocimiento de estos principios para su adecuada aplicación. 


\section{BIBLIOGRAFÍA}

- FERRER MaC-GREGOR, Eduardo (Coordinador). (2005). Interpretación Constitucional. Tomo I, Editorial Porrúa, México.

- HERNÁNDEZ VALLE, RUBÉN. (1995). Derecho procesal constitucional. Editorial Junicentro. San José, Costa Rica.p. 94.

- JIMÉNEZ CAMPO, JAVIER. (1998). "Sobre la cuestión de inconstitucionalidad". En: RUBIO LLORENTE, FRANCISCO y JIMÉNEZ CAMPO, JAVIER. Estudios sobre jurisdicción constitucional. Editorial MacGraw Hill, Colección Ciencias Jurídicas, Madrid. p. 195.

- OLANO GARCÍA, Hernán Alejandro. (2009). Hermenéutica Constitucional. Grupo Editorial Gustavo lbáñez, Bogotá, D.C.

- VENTURAROBLES, MANUEL E. (2003). Los principales aportes del Juez Rodolfo E. Piza Escalante a la Corte Interamericana de Derechos Humanos (1979 - 1988). En: Justicia, libertad y derechos humanos. Ensayos en homenaje a Rodolfo E. Piza Escalante. Instituto Interamericano de Derechos Humanos, Sala Constitucional de la República de Costa Rica, Corte Interamericana de Derechos Humanos, Colegio de Abogados de la República de Costa Rica. Tomo I. San José, Costa Rica. pp. 270275.

- CARPIO MARCOS, EDGAR. En: FERRER MaC-GREGOR, Eduardo (Coordinador) (2005). Interpretación Constitucional. Tomo I, Editorial Porrúa, México. p. 328.

- HERNÁNDEZ VALLE, RUBÉN. (1995). Derecho procesal constitucional. Editorial Juricentro. San José, CostaRica. p. 94. 